\title{
Chemical Composition and Characteristic Odor Compounds in Essential Oil from Alismatis Rhizoma (Tubers of Alisma orientale)
}

Mitsuo Miyazawa* , Seiji Yoshinaga, Yusei Kashima, Hiroshi Nakahashi, Nobuyuki Hara, Hiroki Nakagawa and Atsushi Usami

Department of Applied Chemistry, Faculty of Science and Engineering, Kinki University (Kindai University), 3-4-1 Kowakae, Higashiosaka-shi, Osaka 577-8502, JAPAN

\begin{abstract}
Chemical composition and potent odorants that contribute to the characteristic odor of essential oil from Alismatis Rhizoma (tubers of Alisma orientale) were investigated by gas chromatography-mass spectrometry (GC-MS), GC-olfactometry (GC-O), aroma extract dilution analysis (AEDA) and relative flavor activity (RFA) methods. Fifty components, representing $\mathbf{9 4 . 5 \%}$ of the total oil, were identified. In this study, we newly identified thirty-nine compounds in the oil from tubers of $A$. orientale. The major constituents of the essential oil were khusinol $(36.2 \%)$, $\delta$-elemene $(12.4 \%)$, germacron $(4.1 \%)$, alismol $(3.8 \%)$, $\beta$-elemene $(3.1 \%)$, and $\alpha$-bisabolol $(1.9 \%)$. Through sensory analysis, sixteen aroma-active compounds were detected and the key contributing aroma-active compounds were $\delta$-elemene (woody, flavor dilution (FD)-factor $=4$, RFA $=0.3$ ) $\beta$-elemene (spicy, FD = 5, RFA = 0.7), spathulenol (green, FD = 5, RFA = $1.0), \gamma$-eudesmol (woody, FD $=6$, RFA $=1.5)$, and $\gamma$-cadinol $($ woody, $F D=5$, RFA $=1.0)$. These compounds are thought to contribute to the odor from tubers of $A$. orientale. These results imply that the essential oil from the tubers of $A$. orientale deserve further investigations in the phytochemical and medicinal fields.
\end{abstract}

Key words: Alismatis Rhizoma, Alisma orientale, essential oil, aroma extract dilution analysis (AEDA), relative flavor activity (RFA)

\section{INTRODUCTION}

Crude drugs or herbal medicines ( Kampo" in Japanese) have been used for more than 2,000 years to treat various diseases in Japan, China, and Korea owing to their natural healing power. The pharmacological activities of crude drugs are attributed to their active ingredients such as volatile oils and volatile compounds, which impart aroma and flavors. We have been involved in the study of these compounds, in several crude drugs for a long time ${ }^{1-9)}$.

Alisma orientale belongs to family Alismataceae and is widely cultivated in China and Japan. Alismatis Rhizoma (the dried tubers of $A$. orientale), termed Ze Xie in Chinese Pharmacopoeia, is a traditional Chinese medicine for the treatment of hyperlipidemia and diabetes and is used as a diuretic ${ }^{10)}$. Previous phytochemical investigation has shown that the main chemical constituents of the dried tubers of A. orientale ("takusha" in Japanese) are various terpenoids, including sesquiterpenoids, diterpenoids, and triterpenoids ${ }^{10-12)}$. In the supercritical $\mathrm{CO}_{2}$ extract and headspace extraction, twenty-seven and seventeen compounds were reported, respectively ${ }^{13,14)}$. However, there are no detailed reports on the aroma-active compounds of essential oil from the tubers of $A$. orientale.

In flavour analysis, GC-olfactometry (GC-O) is the most commonly used method for the evaluation of odorants, GC-O coupled with aroma extract dilution analysis (AEDA) is a particularly useful method for estimating the contributions of the most aroma-active compounds ${ }^{15)}$. The significant contribution of each odorant to the characteristic flavor can be determined by relative flavor activity (RFA). The higher flavor dilution(FD)-factors are often related to the aroma-active compounds, but a high FD-factor for the compounds may be caused by their high oil content. Therefore, RFA is calculated, which takes into consideration both the FD factor and percentage weight of each compound $^{16,17)}$.

The aim of this study is to investigate the chemical composition of essential oil extracted from the tubers of A. ori-

\footnotetext{
*Correspondence to: Mitsuo Miyazawa, Department of Applied Chemistry, Faculty of Science and Engineering, Kinki University (Kindai University), 3-4-1 Kowakae, Higashiosaka-shi, Osaka 577-8502, JAPAN

E-mail: miyazawa@apch.kindai.ac.jp

Accepted September 30, 2015 (received for review July 20, 2015)

Journal of Oleo Science ISSN 1345-8957 print / ISSN 1347-3352 online

http://www.jstage.jst.go.jp/browse/jos/ http://mc.manusriptcentral.com/jjocs
} 
entale, and to evaluate its characteristic aroma-active compounds by AEDA and RFA methods.

\section{EXPERIMENTAL}

\subsection{Plant material}

Dried tubers of A. orientale (Lot. 517111) were obtained from Ohsugi Pharmaceutical Co., Ltd. (Osaka, Japan) and used for extracting the essential oil.

\subsection{Isolation of the volatile oil}

Dried tubers of $A$. orientale (100 g) were subjected to hydrodistillation for $3 \mathrm{~h}$ using a Likens-Nickerson type apparatus with diethyl ether as the extraction solvent to yield $0.17 \%(\mathrm{w} / \mathrm{w})$ of yellowish oil. This oil was dried over anhydrous sodium sulfate and stored at $4^{\circ} \mathrm{C}$ prior to analysis.

\subsection{GC-MS}

An Agilent 6890N gas chromatography-5973 MSD mass spectrometer was used for the GC-MS analysis. The samples were analyzed using a fused-silica capillary columns, HP-5MS (5\% phenyl $95 \%$ polydimethylsiloxane, $30 \mathrm{~m} \times 0.25 \mathrm{~mm}$ i.d., film thickness $=0.25 \mu \mathrm{m})$ and DB-WAX (polyethylene glycol, $15 \mathrm{~m} \times 0.25 \mathrm{~mm}$ i.d., film thickness $=$ $0.25 \mu \mathrm{m})$. The oven temperature was programmed to increase from 40 to $260^{\circ} \mathrm{C}$ at the rate of $4^{\circ} \mathrm{C} / \mathrm{min}$ and held at $260^{\circ} \mathrm{C}$ for $5 \mathrm{~min}$. The flow rate of the carrier gas $(\mathrm{He})$ was $1.5 \mathrm{~mL} / \mathrm{min}$. On the DB-WAX column, the oven temperature was increased from $40^{\circ} \mathrm{C}$ to $240^{\circ} \mathrm{C}$ at the rate of $4{ }^{\circ} \mathrm{C} /$ min and held at $240^{\circ} \mathrm{C}$ for $5 \mathrm{~min}$. The injector and transfer line temperatures were $230^{\circ} \mathrm{C}$, and the ionization energy was $70 \mathrm{eV}$. The mass range was 39-450 amu. One $\mu \mathrm{L}$ of the sample was injected, and the split ratio maintained was $1: 40$.

\subsection{Sniffing test}

A trained panel of sensory evaluation specialists measured the odor intensities of the main aromatic constituents of dried tubers from A. orientale. Twelve panelists, aged 21-26 years (10 males and 2 females, members of Kinki University, Japan), participated in this study. Sensory analysis sessions were performed only after suitable training $(>30 \mathrm{~h})$. The sniffing test by GC-O was carried out using an Agilent Technologies-6890N gas chromatograph equipped with an Agilent 5973 MSD mass spectrometer and sniffing port ODP2(Olfactory Detector Port 2, Gerstel). The GC instrument was equipped with an HP-5MS column (5\% phenyl $95 \%$ polydimethylsiloxane, 30 $\mathrm{m} \times 0.25 \mathrm{~mm}$ i.d., film thickness $=0.25 \mu \mathrm{m}$ ). The samples were injected into the GC in splitless mode. The GC eluent from the capillary column was split in a $1: 1(\mathrm{v} / \mathrm{v})$ ratio between the mass spectrometer and the sniffing port. The oven conditions, injector and transfer line temperatures, carrier gas, flow rate, and ionization mode were the same as those described above for the GC-MS.

\subsection{AEDA}

The results were expressed in terms of the FD factor, which is the ratio of the concentration of the odorant in the initial volatile oil to its concentration in the most diluted volatile oil in which the odor can be still detected by GC-O. The highest sample concentration $(1 \mathrm{mg} / \mathrm{mL})$ was assigned an FD factor of 1 . The volatile oil was diluted stepwise with diethyl ether $(1: 1, \mathrm{v} / \mathrm{v})$, and aliquots of the dilutions $(1 \mathrm{~mL})$ were evaluated. The process was stopped when the evaluators detected no aroma for a certain dilution.

\subsection{RFA}

An odorant with a high FD-factor can be considered as an important contributor to the characteristic flavor. Based on the AEDA results, RFA was calculated using the following equation:

$\mathrm{RFA}=\log \mathrm{FD}$-factor $\left(2^{\mathrm{n}}\right) / S^{0.5}$

where $2^{\mathrm{n}}$ is the FD-factor and $S$ is the weight percentage of a compound ${ }^{16,17)}$.

\subsection{Identification and quantification of compounds}

The compounds were identified by comparing their Retention indices (RIs) and mass spectra with the published data $^{18-26)}$, digital libraries (Mass Finder 4 and NIST02), and Aroma Office version 3.0 (Nishikawa Keisoku Co. Ltd.), which includes 72,120 RI entries of compounds from literature sources. The RIs were calculated using a homologous series of $n$-alkanes $\left(\mathrm{C}_{5}-\mathrm{C}_{28}\right)$ for the HP-5MS column. The quantitative analysis was performed by the internal standard addition method (alkanes $\mathrm{C}_{12}$ and $\mathrm{C}_{19}$ ). The essential oils were diluted $100 \times$ using $\mathrm{Et}_{2} \mathrm{O}$ to achieve a $1 \mathrm{~mL}$ volume, and then $5 \mu \mathrm{L}$ of $\mathrm{C}_{12}-\mathrm{C}_{19}$ solution $(1 \mathrm{mg} / \mathrm{mL})$ was added to the diluted oil. These prepared samples were subjected to GC-MS and GC-FID determinations. The quantitative analysis of the aroma-active compounds of the essential oil were based on the calibration curves for 2 -pentyl furan (peak 1), menthol (peak 3), $\delta$-elemene (peak 6), $\alpha$-cubebene (peak 7), $\alpha$-copaene (peak 9), $\beta$-elemenee (peak 13), $\beta$-caryophyllene (peak 15), $\gamma$-elemene (peak 17), $\gamma$-muurolene (peak 18), calamenene (peak 20), $\alpha$-selinene (peak 22), $\delta$-selinene (peak 23), spathulenol (peak 30), $\gamma$-eudesmol (peak 34), $\gamma$-cadinol (peak 36) and $\beta$-cadinol (peak 40) within the concentration range 0.5$1000 \mu \mathrm{g} / \mathrm{mL}$. The weight-percent of each compound was calculated with response factors to the FID. The results were calculated as the mean values of the injection of the essential oil without correction factors. All determinations were performed in duplicate and averaged. 


\section{RESULTS AND DISCUSSION}

In this study, $0.17 \%$ (w/w) yellowish oil with a woody, spicy, and green odor was obtained as the essential oil. Fifty compounds were identified, representing about $94.5 \%$ of the oil. In this study, we newly identified further thirty-nine compounds in addition to those identified in a previous study ${ }^{13,14)}$. The identified volatile compositions, along with their concentrations and the RIs on the HP-5MS and DB-WAX columns are listed in Table 1.

Sesquiterpenne with a cadinane skeleton, namely, khusinol (peak 37; 36.2\%), is the most abundant compound, followed by $\delta$-elemene (peak $6 ; 12.4 \%$ ), germacrone (peak 19; 4.1\%), alismol (peak 33; 3.8\%), and $\beta$-elemene (peak 13; 3.1\%) (Fig. 1). Khusinol has been reported to be the main compound of the essential oils from vetiver $^{27)}$. In addition, alismol is an unusual sesquiterpene, which is isolated as a characteristic compound from Alismataceae. It is identified as a compound in the oil from tubers of $A$. orientale for the first time ${ }^{28)}$. Alismol mainly inhibiteds $\mathrm{Ca}^{2+}$ influx through a voltage-dependent $\mathrm{Ca}^{2+}$ channels $^{29)}$, acting primarily on nerve terminals and inhibiting their responses to electrical stimulation by interfering with NAD release ${ }^{30)}$. Monoterpenes and sesquiterpenes constituted $0.2 \%$ and $89.1 \%$ in the oil, respectively. In particular, a cadinane and an elemane type were rich in the oil, accounting for $39.0 \%$ and $14.8 \%$, respectively.

In order to gain insight into the potent odorants contributing to the characteristic aroma of $A$. orientale, AEDA method was performed through GC-O analysis ${ }^{31)}$. The aroma-active compounds and their odor properties are shown in Table 2. A comparison of the gas chromatogram obtained by GC using an HP-5MS column and the corresponding FD chromatogram of the odor-contributing compounds is shown in Fig. 1. Based on the FD-factors, it was found that $\gamma$-eudesmol (peak 34; FD $=6$, woody) is the most intense aroma-active compound among sixteen aroma-active com-

Table 1 Chemical composition in the essential oils from tubers of Alisma orientale.

\begin{tabular}{|c|c|c|c|c|c|c|}
\hline \multirow{2}{*}{ No. } & \multirow{2}{*}{ Compounds $^{\mathrm{a}}$} & \multicolumn{2}{|c|}{$\mathrm{RI}^{\mathrm{b}}$} & \multirow{2}{*}{$\begin{array}{c}\text { peak area } \\
(\mathrm{w} / \mathrm{w})\end{array}$} & \multirow{2}{*}{$\begin{array}{l}\text { Identification } \\
\text { method }^{\text {d }}\end{array}$} & \multirow{2}{*}{$\begin{array}{c}\text { Reference } \\
\text { source }^{\mathrm{e}}\end{array}$} \\
\hline & & HP-5MS & DB-WAX & & & \\
\hline$* 1$ & 2-pentyl furan & 990 & 1129 & 0.8 & RI, MS & Wako \\
\hline 2 & allyl hexanoate & 1064 & 1371 & 0.7 & RI, MS & Ardrich \\
\hline 3 & menthol & 1173 & 1636 & 0.2 & RI, MS & Fluka \\
\hline 4 & 2-decanone & 1200 & 1521 & 0.2 & RI, MS & Wako \\
\hline 5 & cyclohexanone & 1268 & 1452 & 0.3 & RI, MS & Wako \\
\hline 6 & $\delta$-elemene & 1327 & 1613 & 12.4 & RI, MS & Wako \\
\hline 7 & $\alpha$-cubebene & 1351 & 1546 & 1.1 & RI, MS & Wako \\
\hline 8 & 1,2-dimethyl-cyclohexene & 1355 & - & 0.3 & RI, MS & TCI \\
\hline$* 9$ & $\alpha$-copaene & 1372 & 1498 & 0.8 & RI, MS & Wako \\
\hline 10 & isoledene & 1379 & 1481 & 0.6 & RI, MS & Wako \\
\hline 11 & 2-butyl-2,7-octadien-1-ol & 1384 & - & 0.5 & RI, MS & TCI \\
\hline 12 & $\beta$-patchoulene & 1387 & 1460 & 0.3 & RI, MS & Wako \\
\hline$* 13$ & $\beta$-elemene & 1391 & 1580 & 3.1 & RI, MS & Wako \\
\hline 14 & cedrene & 1408 & 1588 & 0.4 & RI, MS & Wako \\
\hline$* 15$ & $\beta$-caryophyllene & 1420 & 1636 & 0.7 & RI, MS & Wako \\
\hline 16 & $\gamma$-patchoulene & 1440 & 1684 & 0.6 & RI, MS & Wako \\
\hline$* 17$ & $\gamma$-elemene & 1470 & 1722 & 1.1 & RI, MS & Wako \\
\hline 18 & $\gamma$-muurolene & 1481 & 1671 & 1.0 & RI, MS & Wako \\
\hline 19 & germacrone & 1482 & 1729 & 4.1 & RI, MS & Wako \\
\hline 20 & calamenene & 1492 & 1808 & 0.5 & RI, MS & Wako \\
\hline$* 21$ & $\alpha$-muurolene & 1500 & 1725 & 1.3 & RI, MS & Wako \\
\hline$* 22$ & $\alpha$-selinene & 1507 & 1750 & 0.5 & RI, MS & Wako \\
\hline 23 & $\delta$-selinene & 1509 & 1756 & 0.9 & RI, MS & Wako \\
\hline 24 & $\gamma$-cadinene & 1513 & 1758 & 0.8 & RI, MS & Wako \\
\hline$* 25$ & $\beta$-cadinene & 1518 & 1769 & 1.3 & RI, MS & Wako \\
\hline
\end{tabular}


Table 1 Continued.

\begin{tabular}{|c|c|c|c|c|c|c|}
\hline \multirow{2}{*}{ No. } & \multirow{2}{*}{ Compounds $^{\mathrm{a}}$} & \multicolumn{2}{|c|}{$\mathrm{RI}^{\mathrm{b}}$} & \multirow{2}{*}{$\begin{array}{c}\text { peak area } \\
(\mathrm{w} / \mathrm{w})\end{array}$} & \multirow{2}{*}{$\begin{array}{l}\text { Identification } \\
\text { method }^{\mathrm{d}}\end{array}$} & \multirow{2}{*}{$\begin{array}{l}\text { Reference } \\
\text { source }^{\mathrm{e}}\end{array}$} \\
\hline & & HP-5MS & DB-WAX & & & \\
\hline 26 & 2-cyclohexyl-2-phenyl-propane & 1528 & - & 0.3 & RI, MS & Wako \\
\hline 27 & $\alpha$-bisabolol & 1532 & 1683 & 1.9 & RI, MS & Ardrich \\
\hline 28 & 8,9-dehydro-neoisolongifolene & 1545 & - & 0.7 & RI, MS & Wako \\
\hline 29 & aromadendrene oxide & 1577 & 1833 & 0.6 & RI, MS & Wako \\
\hline$* 30$ & spathulenol & 1581 & 2108 & 1.6 & RI, MS & Wako \\
\hline 31 & cadala-1(10),3,8-triene & 1591 & 1712 & 0.3 & RI, MS & TCI \\
\hline 32 & chiloscyphone & 1614 & 1594 & 0.9 & RI, MS & Wako \\
\hline 33 & alismol & 1622 & 2136 & 3.8 & RI, MS & Ardrich \\
\hline 34 & $\gamma$-eudesmol & 1628 & 1855 & 1.0 & RI, MS & Wako \\
\hline$* 35$ & $\alpha$-copaene-8-ol & 1655 & - & 1.1 & RI, MS & Wako \\
\hline 36 & $\gamma$-cadinol & 1658 & 2210 & 1.5 & RI, MS & Wako \\
\hline 37 & khusinol & 1666 & 2213 & 36.2 & RI, MS & Wako \\
\hline 38 & epi-globulol & 1671 & 2221 & 1.3 & RI, MS & Wako \\
\hline 39 & germacra-4(15),5,10(14)-trien-1a-ol & 1678 & 2226 & 0.9 & RI, MS & TCI \\
\hline 40 & $\beta$-cadinol & 1689 & 2250 & 1.4 & RI, MS & Wako \\
\hline 41 & $(Z)$-nuciferol & 1717 & 2241 & 1.2 & RI, MS & Wako \\
\hline 42 & $\beta$ - $(Z)$-curcumen-12-ol & 1751 & 2232 & 0.5 & RI, MS & Wako \\
\hline 43 & $5 \beta$-eudesma-1,3-dien-11-ol & 1763 & 2236 & 1.3 & RI, MS & TCI \\
\hline 44 & $\begin{array}{l}\text { 2,2,6-trimethyl-1-(3-oxo-but-1-enyl)- } \\
\text { 7-oxa-bicyclo-[4.1.0]-hept-4-en-3-one }\end{array}$ & 1783 & - & 0.5 & RI, MS & Wako \\
\hline 45 & $\begin{array}{l}\text { 3-buten-2-one, } 4-(5,5 \text {-dimethyl- } \\
\text { 1-oxaspiro-[2.5]-oct-4-yl) }\end{array}$ & 1818 & - & 0.4 & RI, MS & Wako \\
\hline 46 & 1,4-dimethyl-7-(1-methylethyl)-azulene & 1825 & - & 0.5 & RI, MS & TCI \\
\hline 47 & isolongifolen-9-one & 1837 & 2321 & 0.4 & RI, MS & Wako \\
\hline 48 & $(Z)$-7-dodecenyl acetate & 1847 & 2153 & 0.6 & RI, MS & Ardrich \\
\hline$* 49$ & ethyl palmitate & 2059 & 2258 & 0.8 & RI, MS & Wako \\
\hline 50 & ethyl linolate & 2244 & 2522 & $\operatorname{tr}^{\mathrm{c}}$ & RI, MS & Wako \\
\hline & hydrocarbons & & & 34.3 & & \\
\hline & alcohols & & & 51.6 & & \\
\hline & ketones & & & 1.3 & & \\
\hline & ethers & & & 1.4 & & \\
\hline & esters & & & 5.9 & & \\
\hline & total identified & & & 94.5 & & \\
\hline
\end{tabular}

${ }^{a}$ Compounds are listed in order of their elution time from a HP-5MS column. Presence of compound is indicated by its GC/FID percentage.

${ }^{\mathrm{b}} \mathrm{RI}$, retention indices determined on HP-5MS and DB-WAX columns, using the homologous series of $n$-alkanes $\left(\mathrm{C}_{5^{-}}\right.$ $\mathrm{C}_{28}$ ).

${ }^{\mathrm{c}} \operatorname{tr}=\operatorname{trace}(<0.1 \%)$

${ }^{\mathrm{d}}$ Identification methods: RI, retention indice; MS, mass spectrum.

${ }^{\mathrm{e}}$ Reference materials were obtained from commercial source and our previous studies: Wako, Wako Pure Chemical Industries Ltd. (Osaka, Japan); TCI, Tokyo Kasei Kogyou Co. Ltd. (Tokyo, Japan); Aldrich, Sigma-Aldrich, St. Louis, MO.

$*=$ previous study 

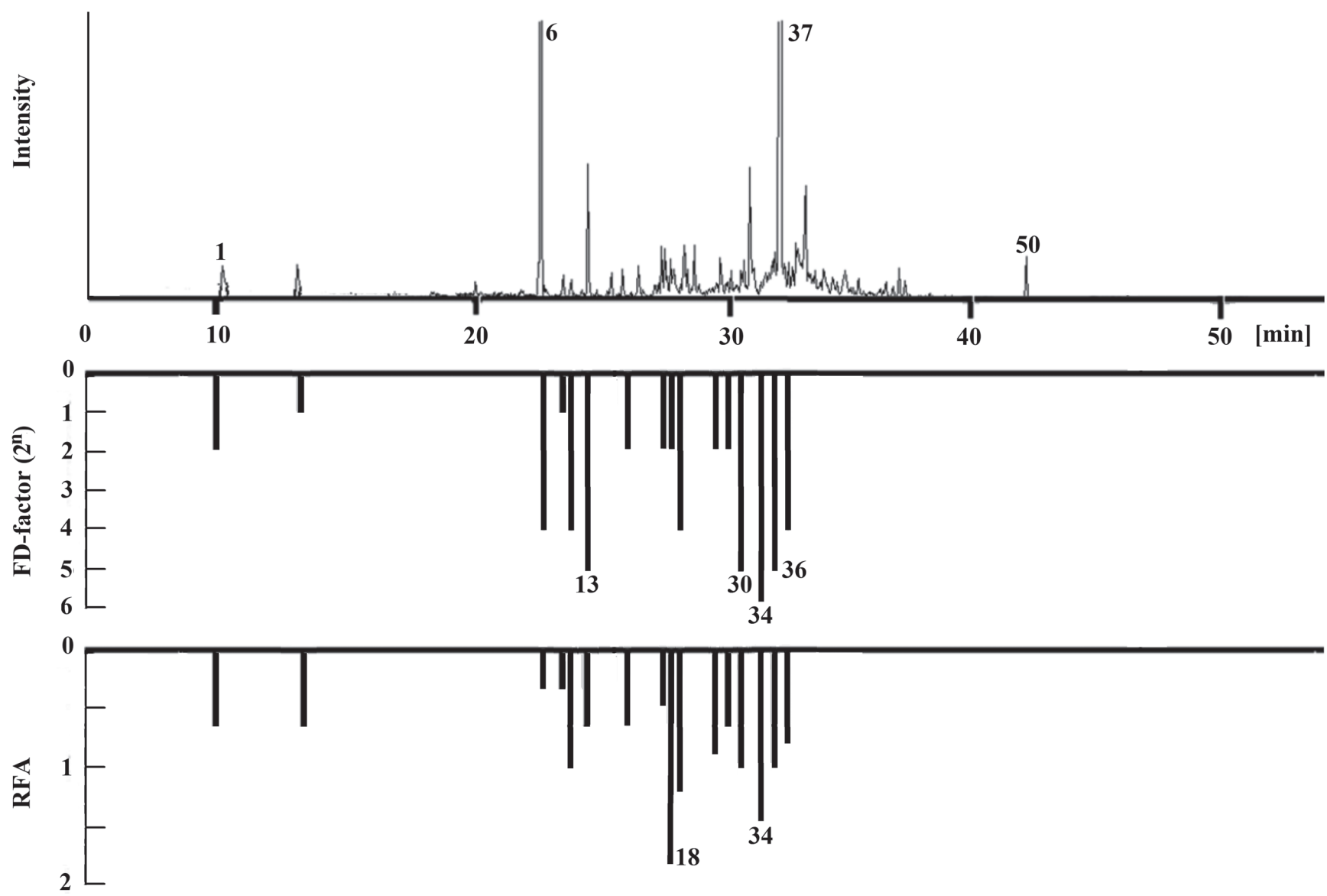

Fig. 1 Gas chromatogram using HP-5MS column and aromagram (FD-factor and RFA) of the essential oil from the tubers of Alisma orientale.

pounds detected by AEDA in the essential oil, followed by $\delta$-elemene (peak 6; FD = 4, woody), $\gamma$-cadinol (peak 36; FD $=5$, woody $), \beta$-elemene (peak 13; FD = 5, spicy), and spathulenol (peak 30; FD =5, green) (Fig. 1). Compounds that are also somewhat involved in the aroma included $\beta$-cadinol (peak 40; FD = 4, woody), calamenene (peak 20; $\mathrm{FD}=4$, spicy), and $\alpha$-copaene (peak $9 ; \mathrm{FD}=4$, spicy) were also involved in the aroma. As a main compound, khusinol was less important among the aroma-active compounds of A. orientale as its FD-factor was not detected. Generally, FD-factors can be considered as an indication of aroma contribution with compounds having a high FD-factor being considered important aroma compounds. However, the high FD-factor of the compounds might be caused by their high content in the oil. They do not always significantly contribute to the aroma because they depend on the compound concentration. Therefore, RFA was calculated which takes into consideration both the FD-factor and the weight percentage of each compound ${ }^{32)}$. The RFA values of the aroma-active compounds in $A$. orientale oil are shown in Table 2. As shown in Fig. 1, the RFA value of $\delta$-elemene is not high in spite of its high FD-factor of 4. Consequently, it can be assumed that the high FD-factor of $\delta$-elemene might be due to its high concentration in the sample. $\alpha$-Copaene, calamenene, spathulenol, $\gamma$-eudesmol, and $\gamma$-cadinol have a high FD-factor $(\geq 4)$ as well as a high RFA $(\geq 1.0)$. These compounds are suggested to be the characteristic aroma-active compounds in the oil from $A$. orientale.

Thus, the highest contribution compounds in the oil were $\delta$-elemene (peak 6 ; RFA $=0.3$ ), followed by $\gamma$-eudesmol (peak 34; RFA $=1.5$ ), and $\gamma$-cadinol (peak 36; $\mathrm{RFA}=1.0$ ). Moreover, $\beta$-elemene (peak 13; RFA =0.7) and spathulenol (peak 30; RFA = 1.0) also contributed essentially to the aroma of the oil at some level. As shown in Table 2 , $\delta$-elemene, $\gamma$-eudesmol, $\gamma$-cadinol, $\beta$-elemene, and spathulenol are ascribed woody, spicy, and green aromas, respectively, by the sniffing test(Fig. 2).

To the best of our knowledge, this is the first study that provides data on the key aroma compounds present in the tubers of $A$. orientale. A total of sixteen aroma-active compounds were determined by the AEDA and RFA methods. Thirty-nine compounds were newly identified in the oil. These results signify that the oil derived from $A$. orientale deserves further investigations in the phytochemical and medicinal fields. 
Table 2 Aroma-active compounds in essential oils from tubers of Alisma orientale.

\begin{tabular}{|c|c|c|c|c|c|}
\hline No. & Compounds $^{\mathrm{a}}$ & $\begin{array}{c}\text { Odor } \\
\text { description }^{\mathrm{b}}\end{array}$ & $\begin{array}{c}\text { peak area } \\
(\mathrm{w} / \mathrm{w})^{\mathrm{c}}\end{array}$ & $\begin{array}{l}\text { FD-factor }{ }^{\mathrm{d}} \\
\left(2^{\mathrm{n}}\right)\end{array}$ & $\mathrm{RFA}^{\mathrm{e}}$ \\
\hline 1 & 2-pentyl furan & sweet & 0.8 & 2 & 0.7 \\
\hline 3 & menthol & $\operatorname{mint}$ & 0.2 & 1 & 0.7 \\
\hline 6 & $\delta$-elemene & woody & 12.4 & 4 & 0.3 \\
\hline 7 & $\alpha$-cubebene & green & 1.1 & 1 & 0.3 \\
\hline 9 & $\alpha$-copaene & spicy & 0.8 & 4 & 1.0 \\
\hline 13 & $\beta$-elemene & spicy & 3.1 & 5 & 0.7 \\
\hline 15 & $\beta$-caryophyllene & spicy & 0.7 & 2 & 0.7 \\
\hline 17 & $\gamma$-elemene & woody & 1.1 & 2 & 0.6 \\
\hline 18 & $\gamma$-muurolene & herbal & 1.0 & 2 & 1.9 \\
\hline 20 & calamenene & spicy & 0.5 & 4 & 1.3 \\
\hline 22 & $\alpha$-selinene & spicy & 0.5 & 2 & 0.9 \\
\hline 23 & $\delta$-selinene & woody & 0.9 & 2 & 0.7 \\
\hline 30 & spathulenol & green & 1.6 & 5 & 1.0 \\
\hline 34 & $\gamma$-eudesmol & woody & 1.0 & 6 & 1.5 \\
\hline 36 & $\gamma$-cadinol & woody & 1.5 & 5 & 1.0 \\
\hline 40 & $\beta$-cadinol & woody & 1.4 & 4 & 0.8 \\
\hline
\end{tabular}

${ }^{a}$ Compounds are listed in order of their elution time from a HP-5MS column.

${ }^{\mathrm{b}}$ Odour quality perceived through the sniffing port.

${ }^{\mathrm{c}}$ These values were computed from the volatile oil yield and GC peak area.

${ }^{\mathrm{d}}$ The sample concentration $(1 \mathrm{mg} / \mathrm{mL})$ was assigned an FD-factor of 1 .

${ }^{\mathrm{e}} \mathrm{RFA}=\log \mathrm{FD}$-factor $\left(2^{\mathrm{n}}\right) / S^{0.5}$, where $S$ is the weight percentage.

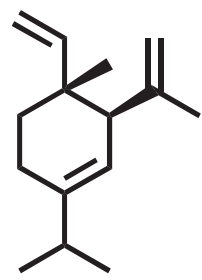

$\delta$-elemene (peak 6) woody

$\mathrm{FD}=4$ RFA $=0.3$

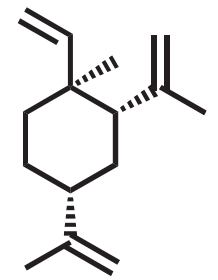

$\beta$-elemene (peak 13) spicy $\mathrm{FD}=5$

$\mathrm{RFA}=0.7$

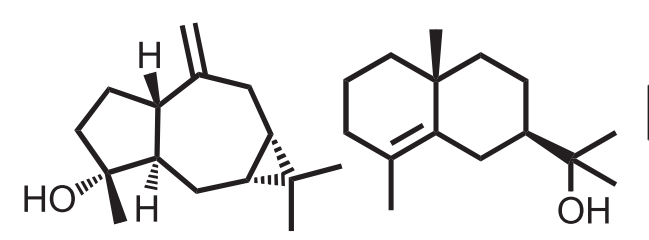

spathulenol (peak 30) green $\mathrm{FD}=5$ $\mathrm{RFA}=1.0$

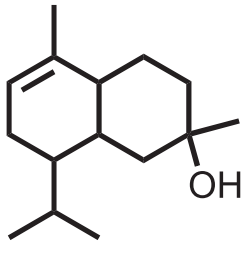

$\gamma$-eudesmol (peak 34) woody $\mathrm{FD}=6$ $\mathrm{RFA}=1.5$ $\gamma$-cadinol (peak 36) woody $\mathrm{FD}=5$ $\mathrm{RFA}=1.0$

Fig. 2 Key aroma-active compounds of the essential oil from tubers of Alisma orientale.

\section{References}

1) Miyazawa, M.; Maruyama, H.; Kameoka, H. Volatile flavor components of crude drugs. Part I. Essential oil constituents of "MOUTAN RADICIS CORTEX" Paeonia moutan Sims. (=P. suffruticosa Andrews). Agric. Biol. Chem. 47, 2925-2927 (1983).

2) Miyazawa, M.; Maruyama, H.; Kameoka, H. Volatile flavor components of crude drugs. Part II. Essential oil constituents of PaAEONIA RADIX, Paeonia lactiflora Pall. (=P. albilora Pall.). Agric. Biol. Chem. 48, 2847-2849 (1984).
3) Miyazawa, M.; Kameoka, H. Volatile flavor components of crude drugs. Part III. Volatile flavor components of ASTRAGALI RADIX (Astragalus membranaceus Bunge). Agric. Bill. Chem. 51, 3153-31548(1987).

4) Miyazawa, M.; Kameoka, H. Volatile flavor components of crude drugs. Part V. Volatile flavor components of ZINGIBERIS RHIZOMA (Zingiber officinale Roscoe). Agric. Biol. Chem. 52, 2961-2963(1988).

5) Miyazawa, M.; Kameoka, H. Volatile flavor components of crude drugs. Part IV. Volatile flavor components of PUERARIAE RADIX (Pueraria lobata Ohwi). Agric. 
Biol. Chem. 52, 1053-1055(1988).

6) Miyazawa, M.; Kameoka, H. Volatile flavor components of crude drugs. Part VII. Volatile flavor components of COMI FRUCTUS (Cornus officinalis Sieb. et Zucc.). Agric. Biol. Chem. 53, 3337-3340(1989).

7) Miyazawa, M.; Fujita, T.; Yamafuji, C.; Matsui, M.; Kasahara, N.; Takagi, Y.; Ishikawa, Y., Chemical composition of volatile oil from the roots of Periploca sepium. J. Oleo Sci. 53, 511-513(2004).

8) Kawata, J.; Kameda, M.; Miyazawa, M. Constituents of Essential Oil from the Dried Fruits and Stems of AKEBIA QUINATA (THUNB.) DECNE. J. Oleo Sci. 56, 59-63(2007).

9) Kawata, J.; Kameda, M.; Miyazawa, M. Cyclooxygenase-2 inhibitory effects and composition of the volatile oil from the dried roots of Lithospermum erythrorhizon. J. Nat. Med. 62, 239-243(2008).

10) Ping, G.; Zhongzhi, Q. Guaiane-type sesquiterpenoids from Alisma orientalis. Phytochemistry 63, 877-881 (2003).

11) Qiang, Y.; Zhang, X.; Liu, H.; Xu, Y. Chemical constituents of Alisma orientalis. Chem. Nat. Compd. 49, 1143-1145 (2013).

12) Jin, H.; kim, A.; Choi, H.; Kim, Y. A New Triterpenoid from Alisma orientale and Their Antibacterial Effect. Arch. Pharm. Res. 35, 1919-1926 (2012).

13) Zhang, Y.; Lin, W.; Xu, R. Determination of supercritical $\mathrm{CO}_{2}$ extract in Alisma orientalis by GC-MS. Zhongyaocai 32, 1700-1702 (2009).

14) Li, L.; Wu, Q. GC-MS analysis of volatile components from headspace extraction of Alisma orieatalis (Sam.) Juzep. Xibei Yaoxue Zazhi 24, 110-113 (2009).

15) Grosch, W. Evaluation of the key odorant of foods by dilution experiments, aroma models and omission. Chem. Senses. 26, 533-545(2001).

16) Song, H. S.; Sawamura, M.; Ito, T.; Ido, A.; Ukeda, H. Quantitative determination and characteristic flavor of daidai (Citrus aurantium. L. var. cyathitera Y. Tanaka) peel oil. Flav. Fragr. J. 15, 323-328(2000).

17) Song, H. S.; Sawamura, M.; Ito, T.: Kawashimo, K.; Ukeda, H. Quantitative determination and characteristic flavour of Citrus junos (yuzu) peel oil. Flav. Fragr. J. 15, 245-250 (2000).

18) Kameoka, H.; Kubo, K.; Miyazawa, M. Volatile flavor components of malabar nightshade (Basella rubra L.) . J. Food Comp. Anal. 4, 315-321 (1991).

19) Miyazawa, M.; Hashidume, S.; Takahashi, T.; Kikuchi, T. Aroma evaluation of gamazumi (Viburnum dilatatum) by aroma extract dilution analysis and odour activity value. Phytochem. Anal. 23, 208-213 (2012).

20) Noudogbessi, J. P.; Yedomonhan, P.; Sohouhloue, D. C. K.; Chalchat, J. C.; Figueredo, G. Chemical composition of essential oil Syzygium guineense (Willd.) DC. var. guineense (Myrtaceae) from Benin. Rec. Nat. Prod. 2, 33-38(2008).

21) Kawata, J.; Kameda, M.; Miyazawa, M. Cyclooxygenase-2 inhibitory effects and composition of the volatile oil from the dried roots of Lithospermum erythrorhizon. J. Nat. Med. 62, 239-243(2008).

22) Zulueta, A.; Maurizi, A.; Frı $\times$ gola, A.; Esteve, M. J.; Coli, R.; Burini, G. Antioxidant capacity of cow milk, whey and deproteinized milk. Int. Dairy J. 19, 380385 (2009).

23) Kurade, N. P.; Jaitak, V.; Kaul, V. K.; Sharma, O. P. Chemical composition and antibacterial activity of essential oils of Lantana camara, Ageratum houstonianum and Eupatorium adenophorum. Pharm. Biol. 48, 539-554 (2010).

24) Misra, A.; Srivastava, N. K.; Srivastava, A. K. Influence of Zn stresses on growth and physiology in Khus-Khus (Vetiveria zizanioides Nash.) and its essential sesquiterpene oil, in relation to roots diameter circumferential positions. Pharm. Biol. 179, 195-198(2011).

25) Ekhteraei, T. S., Radjabian. T.; Ebrahimzadeh, H.; Niknam, V. Composition of essential oils in subterranean organs of three species of Valeriana L. Nat. Prod. Res. 24, 1834-1842(2010).

26) Pisteli, L.; Noccioli, C.; Bertoli, A.; Scapecchi, G.; Potenza, D. Chemical composition and volatile constituents of Anthyllis barba-jovis. Nat. Prod. Res. 21, 418-425 (2007).

27) Kirici, S.; Inan, M.; Turk, M.; Giray, E.S. To study of essential oil and agricultural properties of vetiver (Vetiveria zizanioides) in the Southeastern of Mediterranean. Adv. Environmntal Biol. 5, 447-451 (2011).

28) Oshima, Y.; Iwakawa, T.; Hikino, H. Sesquiterpenoids. Part 58. Alismol and alismoxide, sesquiterpenoids of Alisma Rhizomes. Phytochemistry 22, 183-185 (1983).

29) Matsuda, H.; Kobayashi, G.; Yamahara, J.; Fujimura, H.; Kurahashi, K.; Fujiwara, M. Effects of alismol isolated from Alismatis Rhizoma on calcium-induced contraction in the rabbit thoracic aorta. Life Sci. 41, 18451852 (1987).

30) Matsuda, H.; Yamahara, J.; Kobayashi, G.; Fujimura, H.; Kurahashi, K.; Fujiwara, M. Effect of alismol on adrenergic mechanism in isolated rabbit ear artery. Japanese J. Pharm. 46, 331-335(1988).

31) Schieberle, P.; Grosch, W. Evaluation of the flavour of wheat and rye bread crusts by aroma extract dilution analysis. Z. Lebensm. Unters. Forsch. 185, 111-113 (1987).

32) Hyang, S.; Choi, K. Y.; Sawamura, M. Characterization of the odor-active volatiles in Citrus Hyuganatsu (Citrus tamurana. Hort. Ex. Tanaka). J. Agric. Food Chem. 49, 2404-2408(2001). 